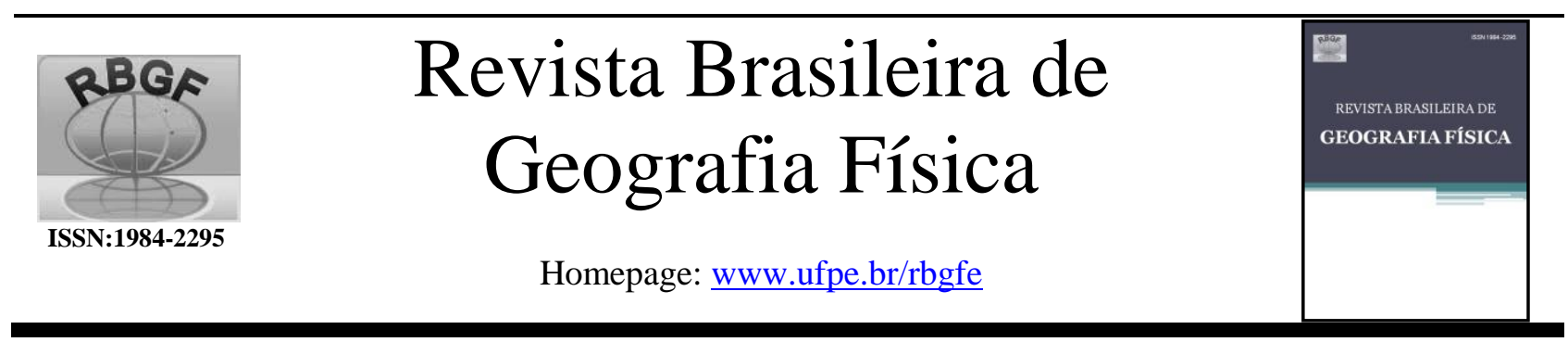

\title{
Sensoriamento remoto aplicado ao monitoramento temporal do eucalipto no município de Grão Mogol - MG
}

\author{
Mariley Gonçalves Borges ${ }^{1}$, Marcos Esdras Leite ${ }^{2}$, Manoel Reinaldo Leite ${ }^{3}$, Hérick Lyncon
}

Antunes Rodrigues ${ }^{4}$

1, 2, 3 e 4 Universidade Estadual de Montes Claros. Autor correspondente e-mail: marileigoncalvesborges@gmail.com

Artigo recebido em 10/04/2018 e aceito em 02/09/2018

\section{R E S U M O}

Com o objetivo de analisar a dinâmica espacial do eucalipto no município de Grão Mogol nos anos de 1994, 2009 e 2015, em função do aumento das áreas de eucalipto no município nas duas últimas décadas, o sensoriamento remoto apresentou grande importância. Essa tecnologia permitiu, por meio da técnica de fotointerpretação, distinguir e delimitar as áreas de eucalipto na imagem de satélite, identificar o local em que estão inseridas e monitorar o seu crescimento nos anos propostos, sendo considerada uma técnica fundamental para estudos ambientais e muito utilizado pelos profissionais da área. A monocultura de eucalipto vem avançando e modificando a paisagem do município de Grão Mogol, estando presente em variadas altitudes e tipologia de solos. Nesse sentido, este estudo é importante para o monitoramento da expansão desse cultivo e seus impactos socioambientais.

Palavras-Chave:Grão Mogol. Eucalipto. Sensoriamento Remoto.

\section{Remote sensing applied to the temporal monitoring of eucalyptus in city of Grão Mogol - MG}

\begin{abstract}
A B S T R A C T
The aim of this work is to analyze the spatial dynamic of eucalyptus in the municipality of Grão Mogol, in the years of 1994, 2009 and 2015, due to the increase of eucalyptus areas in the municipality in the past two decades. In that sense, the remote sensing presented great importance, because permitted through photo interpretation technique to distinguish and delimitate the eucalyptus areas in the satellite image, to identify the place in what they are inserted and monitoring its increasing in the proposed years and; is a fundamental technique for environmental studies and very used by professionals of the area. The eucalyptus monoculture has come advancing and modifying the landscape of the municipality of Grão Mogol, being present in varied heights and typologies of soils and it's seen the necessity of studies and searches for not causing losses and damages to population and biodiversity. Thus, this study is very relevant for monitoring these areas, for the performing of environmental studies and for further impact analysis.

Key-words: Grão Mogol. Eucalyptus. Remote Sensing.
\end{abstract}




\section{Introdução}

Trazido da Austrália para o Brasil no início do século XIX para fins decorativos, o eucalipto foi utilizado para benefício econômico somente após os anos de 1960. No norte de Minas Gerais a monocultura surge através de incentivos fiscais da Superintendência de Desenvolvimento do Nordeste - SUDENE nos anos de 1980, com o propósito de proporcionar desenvolvimento à região (Soares e Nunes, 2013; Santos e Souto, 2014; Barbosa, Silva e Camenietzki, 2014).

No entanto, existem controvérsias sobre os impactos do eucalipto no meio ambiente, para Moura e Zaidan (2017), Vechi e Magalhães Júnior (2018) as plantações de eucalipto contribuem na redução do desmatamento da vegetação e aumenta a quantidade de empregos. Moledo et al. (2016) citam a redução da fragilidade do solo, recuperação das áreas de Mata Ciliar e a conservação do processo de fluxo gênico.

De outra forma, a monocultura de eucalipto apresenta impactos negativos, tais como a concentração de terras (Coelho et al., 2016), poluição dos recursos hídricos e redução da biodiversidade (Lima et al., 2016; Luiz, Faria e Escada, 2016). Há também, perda de nutrientes do solo, expropriação de terras, dentre outros (Mendes, Rodrigues e Santos, 2014).

De acordo com os resultados apresentados por Fonseca e Thomaz Júnior (2014) fatores como migrações de moradores rurais, carência de infraestrutura e baixos salários são consequências do cultivo de eucalipto, realidade que torna este cultivo um indutor de problemas socioambientais.

Embora existam impactos positivos e negativos do cultivo do eucalipto, como as supracitadas, o fato é que sua produção vem aumentando no Brasil, com um total de 4,8 milhões de hectares segundo dados da Associação Brasileira de Produtores de Florestas Plantadas (ABRAF) para o ano de 2015.

Um exemplo do aumento das áreas de eucalipto pode ser encontrado na região norte do estado de Minas Gerais, mais especificamente no município de Grão Mogol (Rodrigues e Costa, 2018). Dentro desta perspectiva, o monitoramento destas áreas se torna de fundamental importância para o planejamento e gestão tanto das áreas passíveis de serem ocupadas pelo eucalipto quanto para estabelecer as áreas de restrições quanto a sua ocupação.

Nesse sentido, para monitorar as áreas de eucalipto em Grão Mogol, as técnicas de sensoriamento remoto apresentam grande auxílio uma vez que podem combinar dados de diferentes fontes e espacializar essas informações em um mesmo mapa.

As técnicas de sensoriamento remoto aplicadas na vegetação fundamentam-se na compreensão da "aparência" do objeto, ou seja, é produto derivado da interpretação do pesquisador relacionado à reflectância do objeto na imagem, fruto de um processo complexo que envolve fatores ambientais (Almeida, Veloso e Nery, 2016; Almeida, Borges e Rodrigues, 2017). No âmbito dos estudos ambientais, a imagem de satélite comumente utilizada é a série Landsat, haja vista que contribui no monitoramento ambiental em função de sua historicidade de cenas (Bertucini Júnior e Centeno, 2016), seu sistema foi iniciado em 1972 pela National Aeronautics and Space Administration (NASA).

O satélite LANDSAT 5 utilizado neste trabalho, foi lançado em março de 1984 contendo 7 bandas espectrais (Zhang e Roy, 2016) e equipado com os sensores TM (Tematic Mapper) e PAN (Pancromático) (USGS, 2013). E, em fevereiro de 2013 foi lançado o Landsat 8, com o sensor OLI contendo 9 bandas espectrais e o sensor TIRS com 2 bandas e, para ser lançado passou por inovações na resolução radiométrica, foram acrescentadas duas bandas espectrais: a new coastal e um novo canal no infravermelho (Roy et al., 2014; Loveland e Irons, 2016; Holden e Woodcock, 2016).

Diante disto, o objetivo deste estudo é analisar a dinâmica espacial do eucalipto no município de Grão Mogol, nos anos de 1994, 2009 e 2015, por meio de técnicas de sensoriamento remoto, a fim de verificar sua localização e expansão. Nesse caso, o presente artigo poderá contribuir a estudos posteriores sobre os efeitos do eucalipto no município de Grão Mogol.

\section{Materiais e Métodos}

\section{Caracterização da área de estudo}

O município de Grão Mogol, conforme figura 1, encontra-se localizado no norte do estado de Minas Gerais entre as coordenadas 16 $6^{\circ}$ ' $20^{\prime \prime}$ e $16^{\circ} 48^{\prime} 0^{\prime \prime}$ de latitude sul, e, $42^{\circ} 30^{\prime} 40^{\prime \prime}$ e $43^{\circ} 16^{\prime} 40^{\prime \prime}$ de longitude oeste, possui uma área de 3.903,62 $\mathrm{km}^{2}$ e uma população total de 15.024. Dessa população, 9.633 habitantes estão na área urbana e 5.391 na zona rural, com uma densidade demográfica de $3,85 \mathrm{hab} / \mathrm{km}^{2}$ (IBGE, 2010). A estimativa da população para o ano de 2017 referese a 15.931 habitantes (IBGE, 2017). 


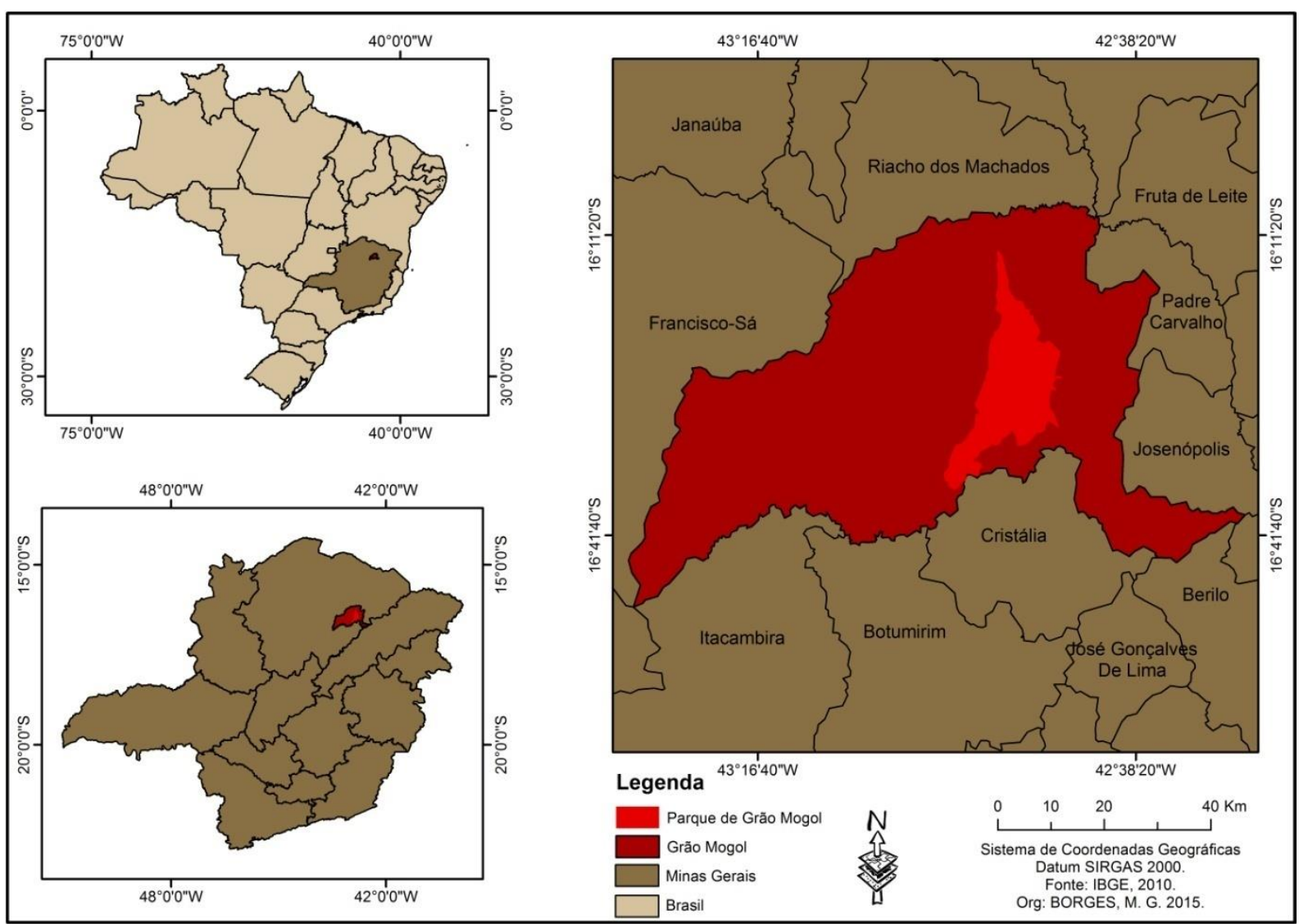

Figura 1: Localização do município de Grão Mogol Fonte: IBGE, 2010.

A renda per capita do município em 2010 era de 293,87 reais, um aumento de $67,81 \%$ em relação aos dados de 1991. Com relação à infraestrutura $57,37 \%$ da população tem água encanada em seus domicílios e 95,59 \% têm energia elétrica, conforme os dados do IBGE (2010). Em relação ao Índice de Desenvolvimento Humano Municipal - IDHM de Grão Mogol está compreendido na faixa de 0,604 em 2010. Entre 2000 e 2010 a população de Grão Mogol cresceu a uma taxa média anual de $0,55 \%$ (PNUD, IPEA e FJP, 2010).

A rede hidrográfica do município em análise é diversificada, sendo que a drenagem possui predominância nas direções nordeste/sudeste e leste/oeste. Os principais rios perenes são: o rio Extrema mais ao centro do município; o rio Ventania, na posição centro-leste, sendo que os dois cursos hídricos mencionados são paralelos; o rio Jequitinhonha, e o rio Itacambiruçu. Outro importante manancial é o rio Vacaria, posicionado no norte do município, caracterizamse pela sua perenidade, ambos pertencem à bacia hidrográfica do rio Jequitinhonha (IBGE, 2010).

O município apresenta sequências metamórficas de origem sedimentar de médio a baixo grau metamórfico, sequências sedimentares principalmente psamíticas, podendo incluir piroclásticas, sedimentos arenosos e argilocarbonáticos desde muito pouco até fraco grau metamórfico. Abrange cinco tipos de solos, são eles o Latossolo Vermelho-Amarelo, Cambissolo Háplico, Neossolo Litólico, Argilossolo Vermelho e Latossolo Vermelho (IBGE, 2010).

Sobre a vegetação do município, têm-se fitofisionomias do Cerrado como o Campo Rupestre, Cerrado sentido restrito e Campo Cerrado (Silva e Parrela, 2013; Borges, Rodrigues e Leite, 2017).

O Parque Estadual de Grão Mogol, inserido neste contexto, foi criado em 22 de setembro de 1998, com área de 33.324,72 hectares apresenta elementos naturais quase não encontrados em outras partes de seu território. Como exemplo, uma fauna diversificada, vegetação variada, rios perenes, entre outros (Silva e Parrela, 2013). Inclusive, o parque se encontra numa das regiões com os maiores índices pluviométricos do município. De acordo com Paulino et al. (2017, p.208) o Parque "[...] visa preservar integralmente a riqueza e a beleza ambiental desta área de grande relevância ecológica e beleza cênica no norte de Minas Gerais". 


\section{Materiais e procedimentos técnicos operacionais}

Para atingir os objetivos propostos, primeiramente foi realizado uma revisão teórica sobre a aplicação do sensoriamento remoto no monitoramento ambiental, logo após, selecionou os anos a serem mapeados e analisados. A escolha dos anos (1994, 2009 e 2015) justifica-se pela expansão do eucalipto após a década de 1990 , e, por serem um dos poucos anos em que havia baixa cobertura de nuvens nas cenas das imagens de satélite Landsat adquiridas.

Para a realização do trabalho, os seguintes produtos foram utilizados:

- Imagem do sensor TM do Landsat 5, órbita/ponto 217/71 e 217/72, 218/ 71 e 218/72 referente ao ano de 1994 e 2009, disponibilizadas gratuitamente pelo Instituto Nacional de Pesquisas Espaciais (INPE) e Imagem do sensor OLI do Landsat 8, órbita/ponto 217/71 e 217/72, 218/ 71 e 218/72 do ano de 2015; disponibilizado gratuitamente através do site da instituição United States Geological Survey (USGS).

- A imagem Shuttle Radar Topographic Mission (SRTM), a carta de 1: 250.000 SE-23-X$\mathrm{B}$, disponível no site da Empresa Brasileira de Pesquisas Agropecuárias (EMBRAPA).

Após a aquisição das cenas, com o intuito de gerar uma imagem multiespectral para cada ponto e órbita que compreende o município, foi utilizado a ferramenta Composit Bands do software ArcGis 10.2. Posteriormente, na opção Georreferencing foi feito o processo de georreferenciamento (ajuste) das cenas para que não houvesse o deslocamento das mesmas, tendo como base a imagem do Landsat 8 , uma vez que ela já vem georreferenciada.

E, por último, na ferramenta Mosaic To New Raster foi realizado o mosaico (junção) das cenas. A fim de vetorizar as áreas de eucalipto no município de Grão Mogol por meio das imagens de satélite,criou-se shapefiles para gerar os polígonos das áreas ocupadas pela monocultura nos anos de 1994, 2009 e 2015.

Para identificar as áreas de eucalipto na imagem de satélite utilizou-se a técnica de interpretação visual de imagens, nesse caso como a reflectância da vegetação é evidente na banda 4 do Landsat 5 e na banda 5 do Landsat 8, ambas representando o infravermelho próximo é um fator que contribui na identificação da cobertura da vegetação. E, como o eucalipto é evidente na imagem devido a sua forma geométrica de plantio em mosaicos, pode-se distinguir precisamente as áreas na imagem de satélite.

A partir dos polígonos vetorizados, calculou-se a área em quilômetros quadrados cobertas por eucalipto, todo o processo foi realizado para cada ano e após todos esses dados gerados e quantificados, foram adicionados em um mesmo layer e sobrepostos de maneira que, fiquem evidentes as áreas de eucalipto de cada ano e a sua expansão.

Logo após, foi feito o cálculo percentual de eucalipto na área do município, e, para gerar dados de altitude utilizou-se a imagem Shuttle Radar Topographic Mission (SRTM), a carta de 1:250.000 SE-23-X-B que é a imagem que compreende o município de Grão Mogol, utilizando o software ArcGis 10.2 foi extraído a área de estudo, logo após, definiu-se em 5 classes de altitude no Simbology e reclassificou a imagem na ferramenta Reclassify do Spatial Analyst Tools.

Com a hipsometria gerada, foram adicionados os polígonos de eucalipto anteriormente gerados para a análise da altitude das áreas em que se encontram as plantações de eucalipto. Logo após, realizou-se uma visita a campo e, com entrevista informal com os moradores rurais de Grão Mogol tornou-se possível analisar espacialmente o eucalipto na região e suas consequências socioambientais.

\section{Resultados e discussão}

Em Grão Mogol, a produção de eucalipto no ano de 1994 era de $421,8 \mathrm{~km}^{2}$ que representa $10,8 \%$ da área do município, as áreas de maior predominância de cultivo eram no leste, nordeste e sudoeste do território municipal. Em 2009, a área plantada de eucalipto aumenta para $546,90 \mathrm{~km}^{2}$ conforme visualizado no gráfico 1 , significando $14,1 \%$ da área municipal, com aumento de $4 \%$ em relação a 1994.

Em 2015, as áreas de eucalipto no município de Grão Mogol correspondem a 678,39 $\mathrm{km}^{2}$ e apresentou aumento de 3,3\% em relação ao ano de 2009. Essas áreas correspondem 17,4\% do município, e sua expansão ocorreu nas mesmas áreas dos plantios anteriores. 
Revista Brasileira de Geografia Física v.11, n.06 (2018) 2046-2056.

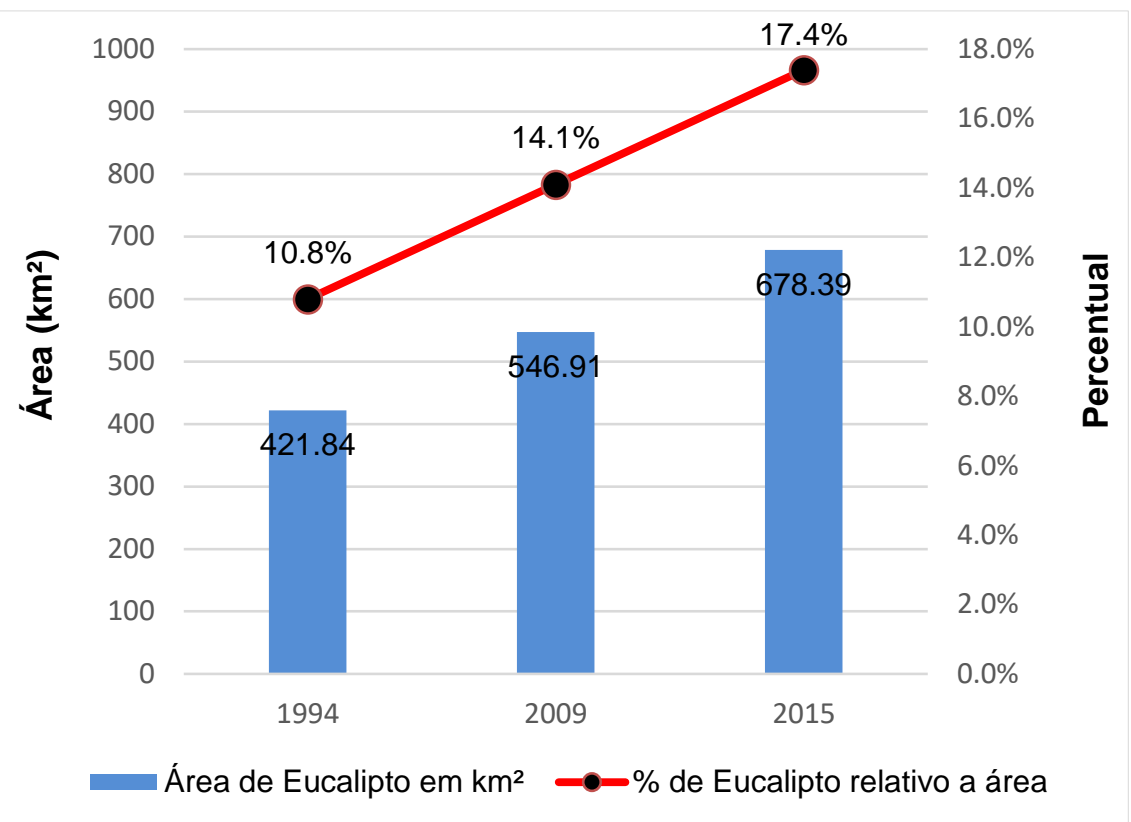

Gráfico 1: Área do município de Grão Mogol ocupada por eucalipto.

Org: RODRIGUES, H. L. A. 2016.

Percebe-se que, os povoados de Giro, Purificação, Curiacá, Maçangana e Cancelas, e a vila de Barrocão estão situados próximos as reservas de eucalipto. As áreas cobertas pela monocultura vêm-se expandindo, principalmente em áreas de recarga hídrica dos cursos d'água como se podem notar na figura 2 , cobrindo as chapadas deste município promovendo a retirada do cerrado que originalmente cobre estas áreas.

No ano de 1994 as áreas de eucalipto estavam presentes em pequenos mosaicos em grande parte do município de Grão Mogol, com concentração maior no nordeste e sudoeste do município. Em 2009, as mesmas áreas anteriores (nordeste e sudoeste) permaneceram, porém houve um grande aumento de plantações de eucalipto na porção noroeste do município, que no ano de 1994 quase não havia, esse aumento ocorreu principalmente próximo à vila de Barrocão, devido à disponibilidade de terras com pequenas quantidades de nutrientes (IBGE, 2010) e disponibilidade de mão de obra.

No ano de 2015 houve ampliação dessas áreas, principalmente no sudoeste do município (Borges e Rodrigues, 2016), com aparecimento de pequenas áreas de cultivo em toda a porção municipal, principalmente ao sul conforme visualizado na figura 2 , visto que são áreas de pouco grau metamórfico e com sedimentos arenosos, além de apresentarem áreas de pouca fertilidade, alta salinidade e não apresenta potencial agrícola, conforme os dados do IBGE (2010). 


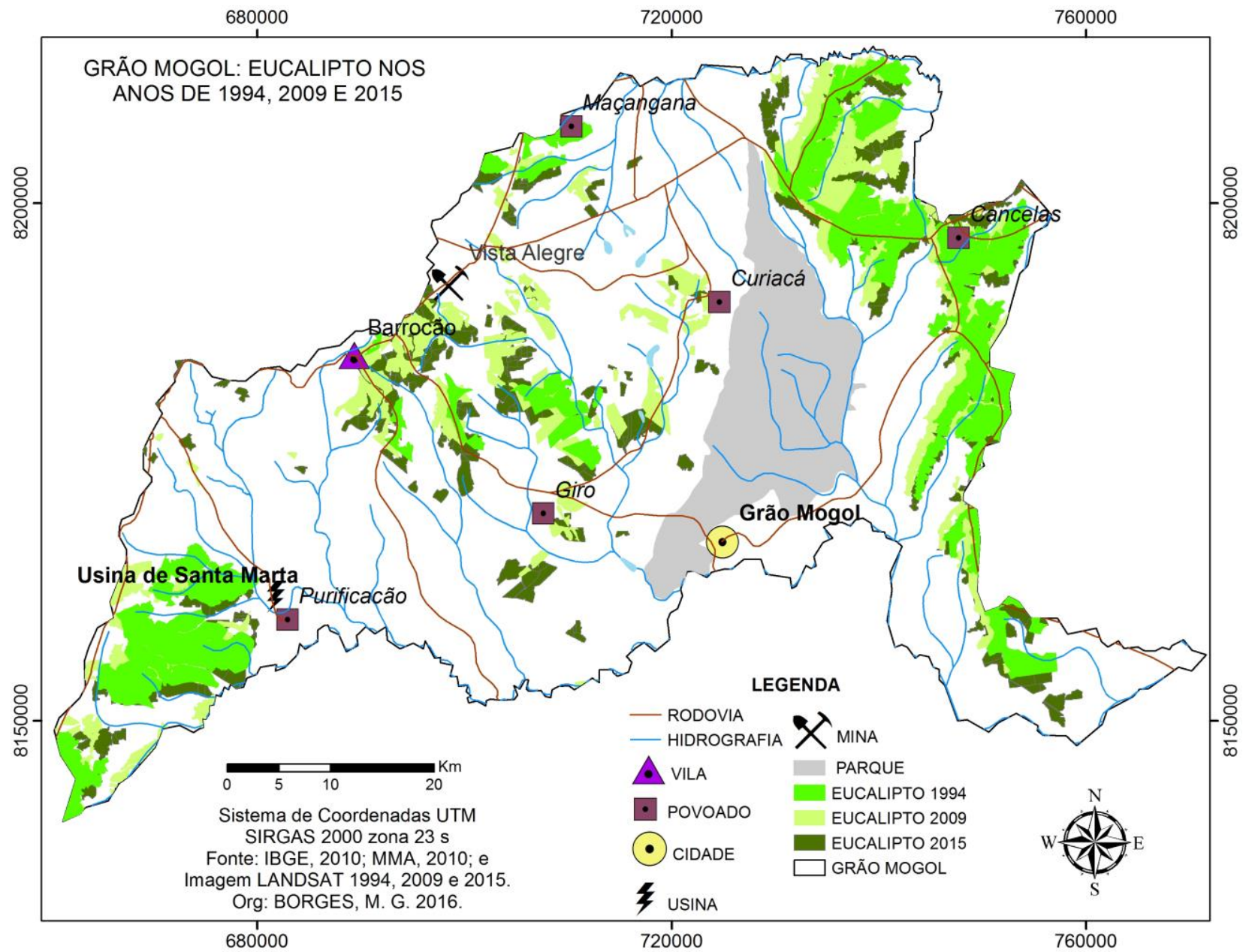

Figura 2: Localização das áreas de eucalipto no município de Grão Mogol.

Fonte: IBGE 2010; e Imagem LANDSAT 1994, 2009 e 2015.

A figura 3 mostra como o cultivo de eucalipto vem avançando, desde chapadas até o entorno da casa do trabalhador rural. Com o levantamento de campo obtido com os moradores, afirmaram plantar algumas unidades de eucalipto no entorno de suas casas para o sombreamento, retirada da madeira para a lenha, postes, caibros, enfim, para a própria subsistência.

Disseram, ainda, que, com a expansão do plantio de eucalipto na região, as chapadas que anteriormente eram utilizados para a solta de animais na época da seca para "descansar" os pastos para o crescimento da pastagem, atualmente já não são mais possíveis, devido à monocultura de eucalipto.

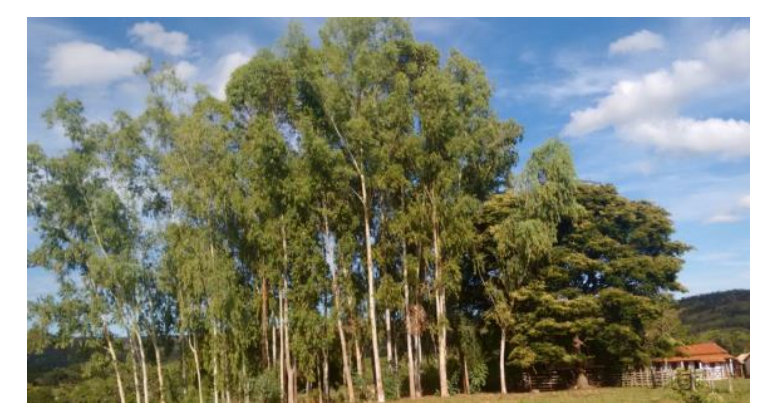

Figura 3: Plantação de eucalipto no entorno da casa do trabalhador rural.

Autor: BORGES, 2015.

Após os anos 2000, a monocultura de eucalipto contribuiu na geração de empregos para várias famílias da região, homens e mulheres trabalham em diversos segmentos oferecidos pelas empresas ali instaladas, tais como a Rima Industrial, Pró-Flora Agroflorestal e Rio Rancho Agroflorestal. 
Através do levantamento de campo com os trabalhadores rurais, descreveram a rotina de seu trabalho diário:
“ Saímos de nossas casas ás 5:00h - 6:00h da manhã em um ônibus da empresa, chegando no serviço às 7:00, levamos nosso almoço e café da tarde e, retornamos para casa somente depois das 17:00 horas da tarde, de segunda a sexta e alguns sábados até o meio-dia, recebendo no final do mês aproximadamente $\quad 900$ reais".

Não somente a população da zona rural trabalha na monocultura de eucalipto como também da zona urbana, pois, as oportunidades de trabalho são poucas, muitos conciliam esse trabalho com a agricultura/pecuária, para não precisar comprar alguns mantimentos, e ter renda extra.

No ano de 1994, a produção de eucalipto estava presente em todas as altitudes que compreende o município de Grão Mogol. Havia aproximadamente $5,15 \mathrm{~km}^{2}$ de eucalipto entre 324 - $750 \mathrm{~m}$ de altitude e $64,24 \mathrm{~km}^{2}$ entre 750,1 - 850 $\mathrm{m}$. A maior quantidade de eucalipto, que corresponde a $214,98 \mathrm{~km}^{2}$ estava localizada em áreas entre $850,1-950 \mathrm{~m}$, seguido por $92,65 \mathrm{~km}^{2}$ entre $950,1-1050 \mathrm{~m} \mathrm{e} 44,82 \mathrm{~km}^{2}$ em áreas superiores a 1050 metros.

Em 2009 houve aumento das áreas de eucalipto em todas as altitudes, exceto em áreas superiores a 1050 metros. Cerca de $13,59 \mathrm{~km}^{2}$ de eucalipto estavam localizadas entre $324-750 \mathrm{~m}$ e $101,35 \mathrm{~km}^{2}$ entre $750,1-850 \mathrm{~m}$. O maior aumento $\left(91,78 \mathrm{~km}^{2}\right)$ ocorreu em áreas com altitude entre $850,1-950 \mathrm{~m}$, apresentando em 2009 aproximadamente $306,76 \mathrm{~km}^{2}$ de eucalipto presentes nessas áreas.

Com $98,59 \mathrm{~km}^{2}$ de eucalipto entre $950,1-$ $1050 \mathrm{~m}$ de altitude, foi o intervalo que obteve o menor aumento $\left(5,94 \mathrm{~km}^{2}\right)$. E as áreas superiores a 1050 metros não tiveram aumento das áreas de eucalipto do ano de 1994 a 2009.

No ano de 2015, houve aumento das áreas de eucalipto em três intervalos de altitude. O maior aumento ocorreu entre 850,1 - $950 \mathrm{~m}$, apresentou em 2015 uma área de $374,55 \mathrm{~km}^{2}$ em seguida temos as áreas que correspondem ao intervalo de 950,1 $1050 \mathrm{~m}$ com $154,51 \mathrm{~km}^{2}$ e áreas superiores a 1050 metros aumentaram a quantidade de eucalipto para $78,48 \mathrm{~km}^{2}$.

No entanto, nos intervalos de altitude entre 323 - 750 m houve redução das áreas de eucalipto, apresentando em 2015 uma área de $1,11 \mathrm{~km}^{2}$. Outra altitude que teve perda das áreas de eucalipto foi entre $750,1-850 \mathrm{~m}$ com $67,79 \mathrm{~km}^{2}$ de eucalipto conforme visualizado na figura 4.

Portanto, as áreas que apresentaram o maior aumento das áreas de eucalipto de 1994 para 2015 foram em altitudes entre 850,1 - $950 \mathrm{~m}(159,7$ $\left.\mathrm{km}^{2}\right)$, seguido por $950,1-1050 \mathrm{~m}\left(61,86 \mathrm{~km}^{2}\right)$ e em áreas superiores a $1050 \mathrm{~m}\left(33,66 \mathrm{~km}^{2}\right)$. Com o menor aumento, foram os intervalos entre 750,1 $850 \mathrm{~m}\left(5,55 \mathrm{~km}^{2}\right) \mathrm{e}$ as áreas inferiores a 750 metros tiveram redução das áreas $\left(-4,04 \mathrm{~km}^{2}\right)$. Nesse sentido, pode-se constatar que a expansão do eucalipto ocorreu em áreas mais elevadas e diminuiu a produção em áreas de pequenas altitudes do ano de 1994 para 2015.

Dentre os cinco tipos de solos existentes em Grão Mogol, o eucalipto só não se encontra presente na pequena área compreendida por Argilossolo Vermelho; a predominâncias de eucalipto ocorre em áreas de Latossolo VermelhoAmarelo que apresentam sequências metamórficas de origem sedimentar de médio e baixo grau metamórfico, seguido de sedimentos arenosos e argilo-carbonáticos desde muito pouco até baixo grau metamórfico. Concentra-se também, em áreas de faixas de dobramentos e coberturas metassedimentares associadas e coberturas metassedimentares do Espinhaço.

Essas áreas na qual o eucalipto encontrase, principalmente situado apresentam baixa fertilidade, baixa disponibilidade de nutrientes, excesso de alumínio, alta salinidade, presença de pedregosidade/rochosidade e textura arenosa, com áreas suavemente onduladas até áreas escarpadas. 


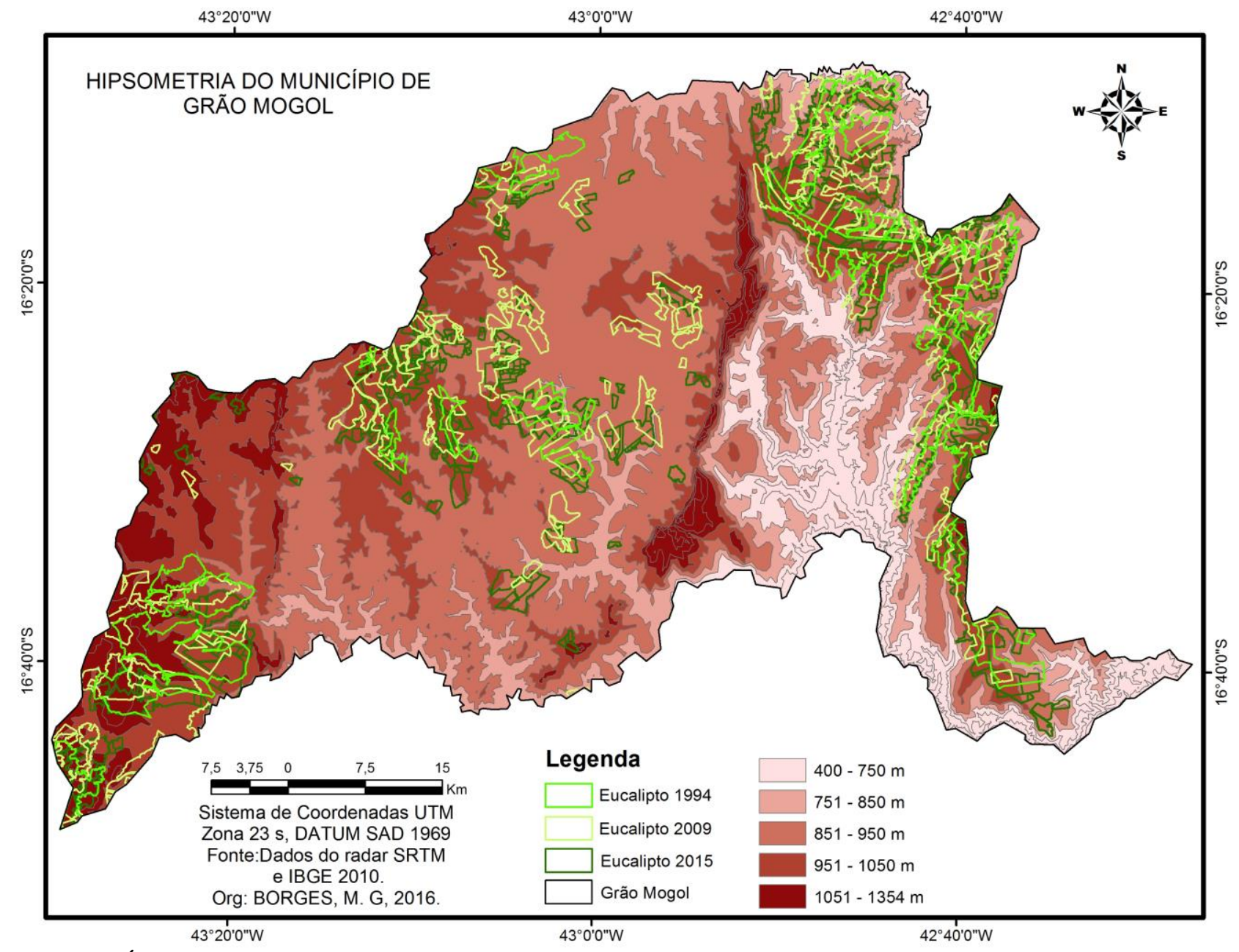

Figura 4: Áreas de altitude no município de Grão Mogol Fonte: Imagem SRTM e IBGE 2010.

As empresas que trabalham com monocultura de eucalipto em Grão Mogol, são: Pró-Flora Agroflorestal LTDA, Minas Ligas, Grupo Plantar, Rima Industrial S/A, e Rio Rancho Agroflorestal S/A. A empresa Rio Rancho é a maior geradora de empregos na região, sendo sua produção voltada para a fabricação de madeira laminada e de chapas de madeira compensada, prensada e aglomerada e também para queima de carvão.

De acordo com Aquino (2013), Moura e Zaidan (2014), Silva e Almeida (2017) a substituição das áreas de Cerrado pelo eucalipto geram alterações pedológicas e hidrográficas. No município de Grão Mogol, em conversa com os moradores rurais da região, afirmaram que alguns rios diminuíram a vazão e outros até secaram. Esses rios em questão, não secaram na montante, $\mathrm{e}$ sim no decorrer do leito do mesmo, (esse rio encontra-se próximo de uma plantação de eucalipto) são rios de primeira e segunda ordem.

$\mathrm{Na}$ figura 5 temos o rio Pé do Morro, localizado nas proximidades da comunidade de Vila-sítio, povoado situado próximo da vila de Barrocão, de acordo com os moradores o rio nunca secava, agora passa a maior parte do ano seco, voltando a correr água somente com as chuvas de novembro a março. 


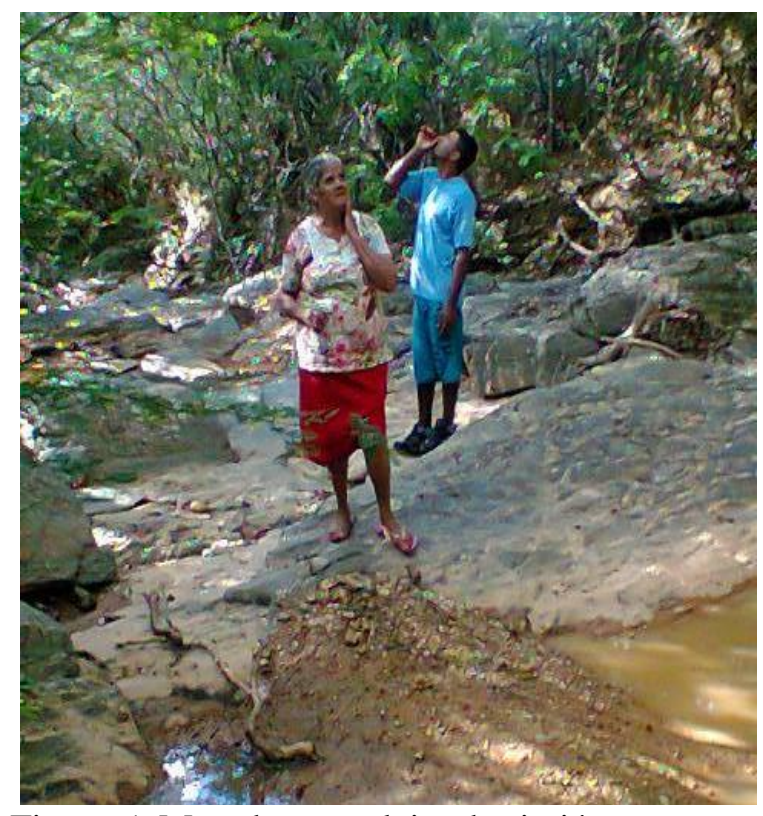

Figura 5: Moradores no leito do rio já quase seco Autor: BORGES, 2015.

A pesquisa não permitiu comprovar se a monocultura de eucalipto está secando os rios da região, embora alguns impactos ambientais fossem bastante perceptíveis, como por exemplo, a compactação dos solos, o represamento de rios para dar acesso a essas áreas e, também para captação d'água para abastecer a monocultura em fase inicial de plantio.

Outro importante fator é a proximidade dos recursos hídricos, que, por estar em determinada altitude, Moura e Zaidan (2017) revelam que, em plantações de eucalipto a água das chuvas chega com mais rapidez ao solo, e quando próximo de um rio poderá causar o assoreamento devido ao processo de carreamento de sedimentos.

Conforme exposto pelos moradores há constatações de que, lençóis freáticos vêm secando devido ao eucalipto, bem como a mudança de uso das chapadas que eram utilizadas para repouso das pastagens, agora utilizadas para a monocultura de eucalipto.

\section{Conclusões}

1) O cultivo de eucalipto no município de Grão Mogol houve um aumento de 37,82\% de área plantada nos últimos 21 anos; sua expansão ocorreu principalmente em áreas superiores a 850,1 metros e apresentou redução de áreas com altitudes inferiores a 850 metros. As áreas ocupadas pela monocultura estão localizadas próximas aos povoados de Cancelas, Maçangana, Purificação, Giro, Curiacá e da Vila de Barrocão devido a disponibilidade de mão-de-obra nessas áreas.
2) Através do levantamento de campo, houve relato dos moradores a respeito da seca dos rios estarem relacionada à plantação de eucalipto, porém, até o momento não temos estudos que comprovaram se é realmente o eucalipto o causador do problema da seca, embora impactos como assoreamentos dos rios e compactação dos solos foram constatados. O que se sabe é a necessidade de estudos sobre impactos ambientais no município para que se for o caso, seja tomado medidas de restauração dessas áreas.

3) O eucalipto vem avançando e modificando a paisagem do município de Grão Mogol, são estradas sendo criadas, vilas aumentando, lugares antes usados para a agricultura e pecuária agora são ocupados pela monocultura de eucalipto.

4) O sensoriamento remoto apresenta grande contribuição no monitoramento das áreas de eucalipto, pois permite fazer análises espaciais e temporais dos alvos de forma rápida, simples e eficiente, com significativa contribuição aos estudos ambientais.

\section{Agradecimentos}

Agradecemos a Fundação de Amparo a Pesquisa em Minas Gerais - FAPEMIG pelo apoio financeiro e a concessão da bolsa de produtividade.

\section{Referências}

Almeida, M.I.S. de., Borges, M.G., Rodrigues, H.L.A., 2017. Análise Comparativa de Fitofisionomias em Áreas de Bacias Hidrográficas do Rio São Lamberto e do Rio Vacaria, Minas Gerais - com Uso de Sensoriamento Remoto. Revista Tocantinense de Geografia 9, 139-156.

Almeida, R.P.de., Veloso, V.H.S., Nery, C.V.M., 2016. Uso do Sensoriamento Remoto para Caracterização de Veredas em Diferentes Estágios de Conservação. Revista Brasileira de Geografia Física 9, 1591-1605.

Aquino, S.L.de., 2013. Contrapondo Interpretações de Agricultores e Pesquisadores sobre Possíveis Problemas Ambientais Causados pelo Cultivo de Eucalipto. Revista Desenvolvimento e Meio Ambiente 28, 127-143.

Barbosa, R.S., Silva, T.P.da., Camenietzki, C.P.de.A., 2014. Direitos Humanos e a Monocultura de Eucalipto: Uma Análise da Comunidade Canabrava, Norte de Minas Gerais. Revista Brasileira de Estudos Jurídicos 9, 121-132. 
Bertucini Júnior, J.J., Centeno, J.A.S., 2016. Registro de Série de Imagens Landsat Usando Correlação e Análise de Relação Espacial. Boletim de Ciências Geodésicas [Online] 22. Disponível em: http://dx.doi.org/10.1590/s1982-

21702016000400039. Acesso em: 17 jul 2018.

Borges, M.G., Rodrigues, H.L.A., 2016. Geotecnologias Aplicadas na Análise dos Indicadores Sociais do Município de Grão Mogol - Minas Gerais. Revista Desenvolvimento Social 19, 73-85.

Borges, M.G., Rodrigues, H.L.A., Leite, M.E., 2017. Mapeamento de Fitofisionomias do Cerrado na Microrregião de Grão Mogol Através de Imagens de Satélite Landsat 8 e Sentinel-2A. Revista Tocantinense de Geografia 10, 19-30.

Coelho, R.M., Leite, A.M.P., Leonel, M.S.; Matuda, J.J., Freitas, L.C., 2016. Avaliação Econômica do Uso da Madeira de Eucalipto para Diferentes Finalidades, na Região do Alto Jequitinhonha, MG. Revista Floresta [Online] $46 . \quad$ Disponível em: http://dx.doi.org/10.5380/rf.v46i2.38600. Acesso em: 17 jul 2018.

Fonseca, S.R.da., Thomaz Júnior, A., 2014. A Consolidação do Complexo de Celulose e Papel na Região Leste de Mato Grosso do Sul: Estudo de Caso do Município de Selvíria. Revista Eletrônica da Associação dos Geógrafos Brasileiros, Seção Três Lagoas 19, 75-103.

Holden, C.E., Woodcock, C.E., 2016. An Analysis of Landsat 7 and Landsat 8 Underflight Data and the Implications for Time Series Investigations. Remote Sensing of Environment [Online] 186. Disponível em: https://doi.org/10.1016/j.rse.2016.02.052. Acesso em: 17 jul 2018.

IBGE. Instituto Brasileiro de Geografia e Estatística, 2010. Disponível em: http://www.ibge.gov.br. Acesso em: 5 nov 2015.

IBGE. Instituto Brasileiro de Geografia e Estatística, 2017. Disponível em: https://cidades.ibge.gov.br/brasil/mg/graomogol/panorama. Acesso em: 19 jul 2018.

Lima, A.R., Girardi, E.P., Mancio, D., Nunes, D.da.C., 2016. Impactos da Monocultura de Eucalipto Sobre a Estrutura Agrária nas Regiões Norte e Central do Espírito Santo. Revista Nera 34, 12-36.

Loveland, T.R., Irons, J.R., 2016. Landsat 8: The Plans, The Reality, and The Legacy. Remote Sensing of Environment [Online] 185. Disponível https://doi.org/10.1016/j.rse.2016.07.033.

Acesso em: 17 jul 2018.

Luiz, C.H.P., Faria, S.D., Escada, M.I.S., 2016. A Expansão do Reflorestamento com Eucalipto e seus Efeitos na Estrutura da Paisagem: Bacia Hidrográfica do Rio Piracicaba e Região Metropolitana Vale do Aço - Minas Gerais. Geografias 12, 64-89.

Mendes, J.de.J., Rodrigues, S.G., Santos, G.R.dos., 2014. Monocultura de Eucalipto e a Questão Territorial: O Caso da Comunidade Vale das Cancelas no Norte de Minas Gerais. Revista Florestan 1, 110-115.

Moledo, J.C., Saad, A.R., Dalmas, F.B., Arruda, R.de.O.M., Casado, F., 2016. Impactos Ambientais Relativos a Silvicultura de Eucalipto: Uma Análise Comparativa do Desenvolvimento e Aplicação no Plano de Manejo Florestal. Revista Geociências 35, 512530.

Moura, A.B.A.P.de., Zaidan, R.T., 2014. Dinâmica Evolutiva da Distribuição Espacial de Plantio de Eucalipto no Município de Lima Duarte, MG - 2005-2011. Revista de Geografia 4, 1-6.

Moura, A.B.A.P.de., Zaidan, R.T., 2017. Análise Multitemporal e Possíveis Impactos da Expansão da Silvicultura de Eucalipto no Município de Carrancas - MG, um Estudo para os Anos de 2005, 2008, 2013 e 2015. Caderno de Geografia [Online] 27. Disponível em: https://doi.org/10.5752/P.2318-

2962.2017v27n48p142. Acesso em: 18 jul 2018.

Paulino, M.T.do.R.O., Freitas, A.M.L.de., Borges, F.M., Freitas, K.K.L.de., Gomes, P.I.J., Dias, R.F.N.C., 2017. Parque Estadual de Grão Mogol - MG: Avaliação de Manejo e sua adequação ao Sistema Nacional de Unidades de Conservação - $\quad$ SNUC. Revista Desenvolvimento Social 21, 207-222.

PNUD. Programa das Nações Unidas Para o Desenvolvimento., IPEA. Instituto de Pesquisa Econômica Aplicada., FJP. Fundação João Pinheiro., 2010. Atlas do Desenvolvimento Humano no Brasil. Disponível em: http://atlasbrasil.org.br/2013/pt/consulta. Acesso em: 19 jul de 2018.

Rodrigues, M.T.S., Costa, J.B.de.A., 2018. Descolonizando os Gerais: Situação Colonial e Estratégias de Resistência das Comunidades Tradicionais Geraizeiras do Norte de Minas Gerais. Revista PerCursos [Online] 19. Disponível em: http://dx.doi.org/10.5965/19847246193920180 77. Acesso em: 18 jul 2018. 
Roy, D.P., Wulder, M.A., Loveland, T.R., Woodcock, C.E., Allen, R.G., Anderson, M.C., Helder, D., Irons, J.R., Jonhson, D.M., Kennedy, R., Scambos, T.A., Schaaf, S.B., Schott, J.R., Sheng, Y., Vermote, E.F., Belward, A.S., Bindsschadler, R., Cohen, W.B., Gao, F., Hipple, J.D., Hostert, P., Huntington, J., Justice, C.O., Kilic, A., Kovalskyy, V., Lee, Z.P., Lymburner, L., Masek, J.G., Mccorkel, J., Shuai, Y., Trezza, R., Vogelman, J., Wynne, R.H., Zhu, Z., 2014. Landsat-8: Science and product vision for Terrestrial Global Change Research. Remote Sensing of Environment [Online] 145.1 Disponível em: https://doi.org/10.1016/j.rse.2014.02.001. Acesso em: 18 jul 2018.

Santos, G.R.dos., Souto, K.G.dos., 2014. O Desenvolvimento no Norte de Minas na Perspectiva da SUDENE. Revista Desenvolvimento Social 12, 69-75.

Silva, M.de.O., Almeida, R.A.de., 2017. Território Rural do Bolsão/MS: A Mobilidade do Complexo Eucalipto/Celulose e seus Impactos em Comunidades Camponesas. Revista Geografia em Questão 10, 77-94.

Silva, C.C.O., Parrela, I.D., 2013. Um Caminho Setecentista dos Garimpeiros para a Bahia, um Parque Florestal na Atualidade: Debates Possíveis sobre a História Ambiental e a
Memória em dois Momentos de Ocupação de uma Serra Diamantina em Minas Gerais. Revista Politeia: História e Sociedade 13, 6788.

Soares, M.P., Nunes, Y.R.F., 2013. Regeneração Natural de Cerrado sob plantio de Eucalyptus camaldulensis Dehn. no Norte de Minas Gerais, Brasil. Revista Ceres [Online] 60. Disponível em: $\quad$ http://dx.doi.org/10.1590/S0034737X2013000200008. Acesso em: 17 jul 2018.

Zhang, H.K., Roy, D.P., 2016. Landsat 5 Thematic Mapper Reflectance and NDVI 27-year Time Series Inconsistencies Due to Sattelite Orbit Change. Remote Sensing of Environment [Online] 186. Disponível em: https://doi.org/10.1016/j.rse.2016.08.022. Acesso em: 17 jul 2018.

USGS. United States Geological Survey, 2013. Disponível em: http://landsat.usgs.gov/about_landsat7.php. Acesso em: 04 out 2015.

Vechi, A.de., Magalhães Júnior, C.A.de.O., 2018. Aspectos Positivos e Negativos da Cultura do Eucalipto e os Efeitos Ambientais do seu Cultivo. Revista Valore [Online] 3. Disponível em:

https://doi.org/10.22408/reva312018101495507. Acesso em: 18 jul 2018. 